\title{
Psychological Microclimate of Student Groups, Studying in Different Instructional Formats
}

\author{
Liudmila Dikaya ${ }^{1, *}$, Olesya Shipitko ${ }^{1}$, and Eugene Borokhovski ${ }^{2}$ \\ ${ }^{1}$ Southern Federal University, B. Sadovay str., 105/42, 344006 Rostov-on-Don, Russia \\ ${ }^{2}$ Centre for the Study of Learning and Performance (CSLP), Concordia University, De Maisonneuve \\ Blvd. West, 1455 Montreal, H3G 1M8 Canada
}

\begin{abstract}
The article discusses psychological microclimate of a student group under different instructional formats (teaching and learning face-toface, online, or blended). The main objective of the study was to explore factors that contribute the microclimate formation in connection with the changes that the formal postsecondary education undergoes because of the COVID-19 pandemic. One hundred and sixty-six students of several higher education institutions in Rostov-on-Don, Russia took part in the study. To fulfill the study objective, data about various individual characteristics of participating students and their subjective rating of the psychological microclimate in the respective student groups were collected by means of psychological testing and subjected first to the ANOVA and then to the multiple regression analyses. ANOVA revealed no statistically significant differences across instructional formats either in the microclimate scores or in the respondents' psychological characteristics. The follow-up multiple regression analysis explored models of joint contribution of the predictor variables to the formation of the microclimate in student groups. Specifically, it found that the relationship between the microclimate and emotional tone is negative, whereas generosity and leadership inclinations are positive predictors of the psychological microclimate in student groups. Better understanding what factors determine dynamic interactions among students in various instructional formats could be instrumental in optimizing microclimate in students group, undoubtedly affected by rather dramatic changes in all aspects of our social lives, caused by the current epidemiological situation in the world. Psychological microclimate in a group is, in turn, capable of seriously impacting on students' learning performance and psychological wellbeing.
\end{abstract}

\section{Introduction}

Since the outbreak of the COVID-19 virus in March 2020, the vast majority of universities in the world has been forced to enter in an experiment unprecedented in history - the closure of campuses and the transfer of the learning process to a distance learning (online) format. Most Russian universities were not an exception - urgently switching to

\footnotetext{
* Corresponding author: dikaya@,sfedu.ru
} 
learning at distance, as well. Six months after the onset of the pandemic, the organization of the educational process in universities has undergone significant changes. By September 2020, some empirical data from sociological and psychological studies of teachers' and students' attitudes to online learning have been accumulated. Their results indicate notable differences in attitudes of major stakeholders in the educational process, depending on the region, composition of the student population, their leading motivation, socio-economic status, psychological and communicative characteristics, etc. [1-7].

Together with the undeniable risks, new opportunities have emerged, as well. Assessing positive and negative aspects of organizing educational process in a distance format, students of higher education institutions in Russian Federation named, as its main "advantages" the convenience of working from home and the opportunity not to commute to and from the venue of study. Among "minuses", there is the lack of interpersonal and social contacts, which represent an important and significant component not only of the learning process, but also of a person's life. This type of deprivation social interactions cannot be ignored, as it is nearly impossible replace them with the surrogate interpersonal communications via online channels [8].

Education in various universities in Russia in the academic year 2020-2021 was not uniformly online, various educational formats - face-to-face, distance and blended coexisted, creating yet another new "field experiment", the consequences of which are not easy to predict. Furthermore, with the pandemic being a persisting reality, the nearest developments of and long-term projections about the formal educational system are unclear. Despite vigorous scientific debate about the effectiveness of educational policy responses to the pandemic-induced challenges, not enough is known about the experiences of effectively applying innovative learning models in new formats. Thus, the problem of finding optimal solutions for organizing students' training in higher education institutions is highly relevant.

Analysis of the recent scientific works of Russian and foreign authors has made it possible to identify and highlight the risks and difficulties, associated with distance education, on one hand, and its advantages, on the other. The most obvious difficulties for students in their transition to distance learning include: psychological (loss of cognitive skills, decreased learning motivation and self-discipline); socio-psychological (lack of direct contact of students with each other and with the teacher, which can slow down the acquisition of new information); social (increasing social isolation, alienation from fellow students and from teachers, cyberbullying and cybertrolling); operational (difficulties in understanding and assimilating study material); health risks for students (visual impairment, development of hypodynamia, depressive conditions, increase in suicidal tendencies and drug abuse); existential and ethical difficulties (virtualization of life, development of digital addictions) and so on [9-13].

The clear advantages of distance education for students include: freedom in choosing the time and place of training, the ability to repeatedly refer to the recording of the lesson; flexible access to training materials and assignments; possible increase in the amount of the studied material, as in comparison with ordinary lessons its presentation may be more illustrative and animated; opportunities to access online lectures of leading teachers and researchers [14-16].

Psychologists also point out to the effectiveness of intellectual and creative research activities in online interactions, shown by participating students [17]. The role of Internetmediated group activities in decision-making, creation of new original ideas and their practical implementation in research is also noted [18]. A multitude of the existing software solutions provide teachers and students with an opportunity to interact in small and large groups united virtually on the Internet to work for a common goal [19]. Overall, the possibility to transfer these constructive experiences of joint activities, aimed at obtaining 
an intellectual product during online communication among participants of the educational process, looks promising.

At the same time, the inability to establish and maintain direct interpersonal psychological contacts either among students of between students and their teachers (including those contacts that heavily rely on non-verbal means of communication) in online instructional formats can cause serious difficulties for all participants of the educational process. The lack of eye contact, physical interactions, facial expressions and gestures, etc. can lead to a decrease in students' interest and motivation for learning and, as a result, impede the effectiveness of education [20-23]. Deprivation of contacts with fellow students and teachers entails subjective perception of the lack of real support and mutual assistance, increases feelings of loneliness, disappointment, and elevated anxiety. Insufficient emotional contacts among students can also create additional problems in the learning itself and preclude students from successfully assimilating study materials. As such, one of the paramount tasks for educators in transition to online learning is to increase opportunities for and support of all types of learners' interactions - student-student, student-teacher, and student-content alike [13, 24, 25].

Changes in interactions in new learning formats inevitably lead to alterations in psychological climate, defined as “... the qualitative aspect of interpersonal relations, which manifests itself in the form of a set of psychological conditions that facilitate or impede productive joint activities and all-round development of the individual in a group" [26, p. 329]. The conditions, in which interpersonal interactions in a students group unfold, as well as their structure and dynamics, affect learners' satisfaction with the educational process, which, in turn, influences the internal motivation of students to learn and, ultimately, the results of learning. Therefore, the problem of forming a favorable psychological microclimate in student groups is becoming relevant in modern education, especially in the current situation.

Psychological microclimate is formed from the very first day a student group is established at the beginning of the first academic year and its members make their first contact. Group microclimate dynamics are quite well described in Russian psychological literature [27]. At the same time, the initial period of joint learning is known to be the most difficult and potentially the most consequential. Students are still poorly oriented in the conditions of the university life and study, they do not know how to interact with each other, or how to coordinate their efforts when performing educational tasks, which could lead to higher energy cost, fatigue, and frustration [28]. The formation of psychological microclimate is influenced by students' individual characteristics and by the nature of their interpersonal relationships. Each individual experiences a favorable microclimate in the group as a state of personal satisfaction with the relationships with fellow students, teachers, the educational process, and learning outcomes. As a result, the mood of a person increases, as does person's motivation for learning, giving a boost to further development of skills and competencies. Therefore, a favorable psychological climate is a condition for the overall increasing interest in and ultimate success of learning. In contrast, an unfavorable climate is experienced by students as dissatisfaction with the group relationships and with learning, in general (including even simple session attendance), i.e., both its context and result. Sketchy, these are the ways, in which the psychological climate of the student group influences academic performance of learners [29, 31]. In the modern research literature, we see information on the role of various factors that contribute to the formation of the psychological climate in student groups, including characteristics of the macro- and microenvironment, personal qualities of individual group members, instructor's teaching style, etc. [28 - 31]. It is quite plausible to assume that the pandemic-caused dramatic changes in educational environments in the universities should also impact on the process of the microclimate formation in student groups. 
To summarize all of the above, we can state the following. Current conditions in our society, in general, and in formal education, in particular is seriously affected by the pandemic in a variety of ways. Of the multitude of factors that can determine either success of failure of students' training in institutions of higher education, the psychological climate plays a particularly important role. Therefore, the study of factors, capable of influencing psychological microclimate formation in student groups under the pandemic and in the post-Covid future, seems more than relevant. Whereas, the research literature provides us with some useful insights regarding factors of the microclimate formation in student groups in regular (face-to-face) instructional formats, much lesser is known about the same processes in distance or blended education. Meanwhile, such data could substantially contribute to finding ways of optimizing teaching and learning in higher education institutions.

The main objective of the present study was to determine how the changing conditions in university education, caused by the COVID-19 pandemic, influence the formation of psychological microclimate in a student group. To successfully meet this objective it was necessary to address the following sequential research questions:

1) Are there differences in psychological characteristics of students across different instructional formats in changing educational conditions?

2) Does instructional format influence the psychological microclimate of the student groups in university?

3) What psychological characteristics of learners predict the psychological microclimate in student groups?

\section{Methodology}

\subsection{Procedure and Participants}

This empirical study was carried out in October 2020, in the middle of the Fall academic semester at several universities in Rostov-on-Don, Russian Federation. Followed the rise of the second wave of COVID-19 contagions, a number of higher educational institutions have completely switched to a distance learning format, while in some, training continued in a face-to-face regular format or adopted some combination of the two. Thus, for the first time in recent history of education, student group formation and interpersonal dynamics within student groups were the subject of serious change on such a massive scale, including bringing together students who never before experienced direct interpersonal contacts with one another.

Overall, 166 students (119 females and 47 males), ranging in age from 17 to 48 (with the average of 21.5), took part in the study. They represented social, humanitarian and technical subject matters and specialties of participating higher educational institutions. The division of the study participants into groups was based on the criterion of the degree of possibility to enable and maintain direct interpersonal contacts among students in the study group. According to requirements and affordances of a particular university/department that took into account, primarily, the discipline and the years of study, participants were divided into four distinctive groups, at least three of which were facing atypical learning format while students in the fourth group, though set-up to study face-to-face, were well aware of the ongoing changes in the learning environments all around them:

1) first-year students, whose training by the time of this study had been carried out in all disciplines in a distance format. These students were not previously experienced face-toface learning, supposedly did not have interpersonal contacts outside class time and 
continued studying in their formal groups online $\left(n_{1}=36\right)$. Lectures and practice sessions for them were conducted by means of the MS Teams platform;

2) first-year students whose training at the time of this study had been carried out in a mixed format, i.e., lectures were conducted on the MS Teams platform, while practical classes were held in-person $\left(n_{2}=49\right)$. All students in this group were directly acquainted with their classmates and saw each other in practical classes two or three days a week, where they had opportunities for interpersonal communications;

3) fourth-year students who, prior to the pandemic onset, i.e., until March 2020, had studied in person full-time, but since then have switched to studying in a distance format using the MS Teams platform $\left(n_{3}=11\right)$. During the previous academic years, these students developed interpersonal relationships in their respective groups, but during this research project, they could maintain those relationships only indirectly, in the online format;

4) students of I-IV year of study, whose learning full-time in-person format continued uninterrupted by the pandemic. These students, therefore, regularly engaged into direct interpersonal contacts with each other, though obviously knew about the massive change in instructional delivery modes anywhere in higher education $\left(n_{4}=70\right)$.

\subsection{Measures}

Our study employed the following psycho-diagnostic instruments offered to the respondents vial Google online forms:

- "Assessment of mental activation and emotional tonus", designed to assess respondents' psychological states. The technique is a modified stimulus material for the SAM technique (Subjective feeling of well-being, Activity, Mood) [32]. A participant is asked to rate twenty polar statements about mental states, as they apply to him/her, on a scale from 0 to 3. The test allows drawing a conclusion about the degree of experiencing the following mental state - mental activation, interest, emotional tonus, tension, and comfort. Each of these five dimensions can collect from 3 to 21 points to reflect the unique pattern of each participant's current mental state.

- Assessment of microclimate in a student group was carried out by means of the ASMGtest [33]. The respondents rated twenty characteristics of microclimate of their respective student groups on a scale from 0 to 3 , resulting in a total score with a theoretical range from 0 to 60 points that reflects their overall opinion of how favourable the microclimate in their group is.

- T. Leary's test of interpersonal relationships was employed to identify the prevalent type of the respondents' attitude towards other people [34]. The questionnaire contains 128 value judgments, which describe eight types of relationships (16 items per type/scale). Judgment statement reflecting each type of relationships are grouped in clusters of four and repeated after an equal number of other clusters. The statements, with which the respondent agrees, are then summed-up to reflect the degree of manifestation of each type of the relationships. Thus, the theoretical range of each scale is in between 0 and 16 points. These are the types of attitudes towards others encompassed by the instrument: dominant, independent, aggressive, distrustful, submissive, dependent, cooperative, and generous.

- The test for assessing communicative and leadership organizational aptitudes is aimed at indirectly identifying these potential human abilities [35]. The questionnaire contains 40 questions, 20 of which address communicative inclinations, whereas the other 20 characterize organizational ones. The corresponding scores obtained using this technique can vary from 0 to $\mathrm{I} 00$ on each scale.

\subsection{Statistical Analyses}


Descriptive statistics for the collected data (means and standard deviations) reflect the magnitude and variability of students' personal characteristics, the microclimate in their respective groups and communicative and organizational inclinations. Analysis of variance (ANOVA) was used to determine if the teaching format differentially affects the microclimate of student groups under new circumstances of the organization and implementation of the educational process. Finally, multiple regression analysis was performed to explore the joint contribution of particular personal characteristics of participants to the microclimate in student groups. Data processing was carried out using the SPSS 23.0 software package.

\section{Results}

Descriptive statistics of all variable assessed in this study are summarized in Table 1 below.

Table 1. Descriptive statistics

\begin{tabular}{|l|l|l|l|l|l|}
\hline Variable & Min & Median & Mean & Max & SD \\
\hline Age & 17 & 19 & 21.5 & 48 & 7.37 \\
\hline Year of study & 1 & 1 & 1.3 & 4 & 0.87 \\
\hline Mental activation & 3 & 12 & 11.5 & 21 & 4.51 \\
\hline Interest & 3 & 9 & 9.5 & 21 & 4.24 \\
\hline Emotional tonus & 3 & 8 & 8.2 & 20 & 3.61 \\
\hline Tension & 3 & 11 & 10.5 & 19 & 3.40 \\
\hline Comfort & 3 & 10 & 9.9 & 19 & 3.30 \\
\hline Microclimate evaluation & 1 & 32 & 32.2 & 54 & 13.6 \\
\hline Dominant & 1 & 4 & 4.5 & 14 & 3.37 \\
\hline Independent & 1 & 4 & 4.2 & 14 & 2.64 \\
\hline Aggressive & 1 & 4 & 4.2 & 13 & 2.58 \\
\hline Distrustful & 1 & 4 & 4.1 & 15 & 2.97 \\
\hline Obedient & 1 & 4 & 4.4 & 12 & 2.60 \\
\hline Dependent & 1 & 4 & 3.9 & 9 & 2.08 \\
\hline Cooperative & 1 & 5 & 5.4 & 13 & 3.01 \\
\hline Generous & 1 & 5 & 5.5 & 13 & 3.02 \\
\hline $\begin{array}{l}\text { Communicative } \\
\text { inclinations }\end{array}$ & 1 & 60 & 56.2 & 100 & 29.9 \\
\hline Leadership inclinations & 10 & 65 & 62.3 & 100 & 18.3 \\
\hline
\end{tabular}

As it is evident from Table 1, emotional states of tension and mental activation are prevalent in all groups, whereas indicators of comfort and interest are less pronounced, and there is also a notable low level of emotional tonus. Analysis of indicators of interpersonal relationships in a group shows relatively high degree of generosity and cooperation, followed in magnitude by the traits of dominance and submissiveness (approximately equal to one another). Identical values are also observed for the indices of independence and aggressiveness, whereas characteristics of distrust and dependency are quite low. It could be surmised that participating students are open to new experience, strive to control the situation, while adapting to the changes in educational process caused by the pandemic. These characteristics appear to relevant potential contributors to the formation of the psychological microclimate in student groups.

As we know from the research literature, psychological microclimate of a student group is important for educational motivation and, as a result, for the academic performance of 
students in face-to-face education [28-31]. The literature also provides data on the influence of a specific instructional format on students' learning [8, 13-23]. Therefore, we next addressed the question of the influence of an instructional format on the microclimate of student groups in higher education institutions.

ANOVA (analysis of variance) was carried out to determine if the Instructional Format factor creates differences in psychological microclimate across participating student groups in the context of new challenges associated with the epidemiological situation in the Russian Federation and in the world. The results showed that there were no statistically significant differences among groups $(F=1.168$ with $p=.172)$ in scores of the microclimate evaluation. In other words, whatever changes the psychological microclimate goes through due to the current challenges faced by educational system, should be typical for all students regardless what instructional format they are studying in.

Based on these data, we then performed multiple regression analysis in order to explore what factors contribute to the formation of psychological microclimate, as the criterion variable, for the entire sample. Its statistically significant results are presented in Table 2. Please, note that we initially tested several regression models with a number of other variables, such as comfort, tension and mental activation, i.e., with the predictors that potentially could most comprehensively reflect the emotional state and involvement of a person in educational and professional activities in changing educational formats.

Table 2. Results of the multiple regression analysis of the connection between psychological microclimate (criterion variable) and selected psychological characteristics of the respondents (independent predictors)

\begin{tabular}{|l|l|l|l|}
\hline \multirow{2}{*}{$\begin{array}{c}\text { Model } \\
\text { Parameters }\end{array}$} & \multicolumn{3}{|c|}{ Psychological microclimate evaluation scores } \\
\cline { 2 - 4 } & $\begin{array}{l}\text { Model 1 } \\
\text { Emotional tonus }\end{array}$ & $\begin{array}{l}\text { Model 2 } \\
\text { Emotional tonus } \\
\text { Leadership } \\
\text { inclinations }\end{array}$ & $\begin{array}{l}\text { Model 3 } \\
\text { Emotional tonus } \\
\text { Leadership } \\
\text { inclinations } \\
\text { Generosity }\end{array}$ \\
\hline Standardized $B$ & $-.405^{* *}$ & $-.294^{* *}$ & $\begin{array}{l}.267^{* *} \\
223^{* *} \\
.244^{*}\end{array}$ \\
\hline Adjusted R2 & 0.157 & 0.199 & 0.227 \\
\hline Model & 24.723 & 16.754 & 13.403 \\
\hline F-ratio & 12.6 & 12.33 & 12.11 \\
\hline SE & 1 & 2 & 3 \\
\hline df (regression) & 1 & 125 & 124 \\
\hline df (residual) & 126 & & \\
\hline
\end{tabular}

Note: $1 .{ }^{* *}-p \leq .01 ; 2{ }^{*}-p \leq .05$.

Exploration of the contribution of all potentially relevant independent variables to the assessment of the student group psychological microclimate, carried out by means of the step-wise multiple regression analysis (a step-by-step method was used), revealed the following results. Only three analyzed psychological characteristics, individually and in combination (final adjusted $R^{2}=.23$ ), significantly affect the microclimate in a student group. The final model (Table 2), with positive and negative statistically significant regression coefficients $(p \leq .01$ and $p \leq .05)$, points out specifically to the following indicators of emotional state: emotional tonus, leadership inclinations and generosity. It is 
understood by the authors that this particular combination of predictors composes group members' desire for open interpersonal interaction and the achievement of common group goals. Supposedly, it is what is forming psychological microclimate in student groups under the current situation in education, when the dynamics of the interpersonal interactions cannot stay unaffected by the changes in instructional formats. The obtained models make it possible to refine the research hypothesis by reducing the number of investigated parameters and their interactions in determining what factors contribute to the microclimate of student groups.

\section{Discussion}

The study found the emotional tonus of the respondents was relatively low, whereas the desire for interpersonal interactions, on contrary, was expressed strongly. Combined, this two patterns may be indicative of the respondents' strive to establish closer interpersonal contacts within their respective student groups to counteract depressed emotional tonus. Students, also, may try to maintain more intensive communication with fellow students and with the teachers in order to stabilize and possibly increase mental activity. Please, note that a low emotional tonus itself makes a negative contribution to the group psychological microclimate. In the future it would make sense to pay closer attention to the specifics of the psychological microclimate formation not just across the changing instructional formats, but also within each one of them, while connecting microclimate particularities to student academic performance. Insights from these types of the future analyses may prove very useful for developing specific recommendations for educational practice in higher education institutions. If, as the findings suggest, we consider leadership inclinations a significant positive contributor to a favorable psychological microclimate in new learning environments, a number of points should be sounded out. For example, when planning instructional interventions, to elevate emotional state of students, educators may want consider more intensive use of group projects and other types of team activities, as well as encourage learners' involvement with various student scientific associations.

As shown in many studies carried out before the pandemic, the most important factor in the formation of the psychological microclimate in a student group within the most typical face-to-face educational format, is the nature of interpersonal communications, their specific characteristics, such as depth, intensity, composition of parties involved, designed structured versus random contextual character, etc. Interpersonal communications substantially contribute to knowledge acquisition and group microclimate alike. In the absence of complete and accurate information, tension in relationships, misunderstanding and mistrust grow, conflicts escalate [36, 37]. Our results support these data. Among variables contributing to the student group psychological microclimate in the new educational environments, leadership inclinations and generosity emerged as significant positive predictors. They could be reasonably categorized as personality characteristics that, not surprisingly, manifest themselves, primarily in interpersonal communications. At the same time, our results open up new horizons for the study of this topic, as nearly $75 \%$ of variability in the microclimate evaluation remains largely unexplained and as some of the newly introduced instructional formats persist and may expand their specific influence on students' perception of their respective groups' microclimate and, through it, on various aspects of educational experiences and learning outcomes.

\section{Research limitations and perspectives}


Since the study time frame was rather limited, its findings may be somewhat fragmented, as the effects of introducing new instructional formats in response to challenges of the Covid19 pandemic might not have fully manifested themselves. The results obtained are also not exhaustive. A substantive portion of variability in the criterion variable remains unexplained that definitely warrants further exploration. Potential lack of statistical power (largely attributable of the organizational issues, including partly restricted access to student population) adds to these limitations and calls for the study replication and expansion with a larger sample of participants.

In the future, we plan to supplement and expand our data by repeating the study toward the end of the second academic semester, when it is likely to expect that all studied situational and stable personality characteristics and their relationships with psychological microclimate will be influenced by the changed instructional formats more saliently and consistently. We also intend to recruit a larger sample of participants to increase statistical power of the analyses. All together, this should help determine the effects of instructional formats on the microclimate in student groups with more confidence. With the increased statistical power, we could also expect to detect differences in the microclimate and in respondents' psychological characteristics of students studying in different instructional formats. We also propose to carry studying the influence of instructional conditions on psychological microclimate beyond the pandemic, when some of these formats may be routinely practiced in institutions of higher education and to include assessment of students' academic outcomes and learning activities - educational, creative, social, scientific, etc. in the future research.

\section{Conclusion}

The proposed model of psychological microclimate in a student group makes it possible to look at contribution to it of students' personal characteristics from a new perspective - in connection with the changes the formal educational system undergoes in response to the current epidemiological situation in the world. The characteristics we considered emotional tonus, organizational inclinations, and generosity - are significant predictors of the microclimate formation in student groups. As the latter has undeniable effect on various aspects of students' life, understanding factors that contribute to psychological microclimate has important practical implications. Based on the data obtained in the study, it is advisable to continue this line of research with special attention to the long-term dynamics of the microclimate formation in student groups, taking into account various aspects of interpersonal interactions and in connection with academic outcomes.

Research was financially supported by Southern Federal University, 2021, project No. VNGr-07 / 2020-02-AP)

\section{References}

1. A. G. Zvezdina, A. Grishina, E. Zvezdina, E. Dyakova, University students' attitude to distance learning in situation of uncertainty, E3S Web of Conferences, 210, 18017 (2020) https://doi.org/10.1051/e3sconf/202021018017

2. S. Alqabbani, A. Almuwais, N. Benajiba, F. Almoayad, Readiness towards emergency shifting to remote learning during COVID-19 pandemic among university instructors, E-Learning and Digital Media 2042753020981651 https://doi.org/10.1177\%2F2042753020981651 
3. J.F. Clabaugh, L.J. Duque, Fields, Academic Stress and Emotional Well-Being in United States College Students Following Onset of the COVID-19 Pandemic. Frontiers in Psychology, 12, 628787 (2021) doi: 10.3389/fpsyg.2021.628787

4. E. Denisova, P. Ermakov, I. Skirtach, V. Korkhova, Subjective discomfort and personality traits of university teachers during the COVID-19 pandemic, E3S Web of Conferences, 210, 19021 (2020) https://doi.org/10.1051/e3sconf/202021019021

5. A.V. Grishina, I.V. Abakumova, Informational Behavior in the COVID-19 Pandemic: Psychological Predictors, International Journal of Cognitive Research in Science, Engineering and Education, 8, 59-67 (2020) https://doi.org/10.23947/2334-8496-20208-SI-59-67

6. M. Penado Abilleira, M-L. Rodicio-García, M.P. Ríos-de Deus, M.J. MosqueraGonzález, Technostress in Spanish University Teachers During the COVID-19 Pandemic. Frontiers in Psychology, 12, 617650 (2021) doi: 10.3389/fpsyg.2021.617650

7. S. Tzivinikou, G. Charitaki, D. Kagkara, Distance Education Attitudes (DEAS) During Covid-19 Crisis: Factor Structure, Reliability and Construct Validity of the Brief DEA Scale in Greek-Speaking SEND. Teachers. Technology, Knowledge and Learning, 119 (2020)

8. Expert committee of the Ministry of Science and Higher Education of the Russian Federation: Survey (2020) https://profsobranie.ru/201 (last accessed: 2021/03/18)

9. E. Borokhovski, D. Pickup, R. Tamim, "Emergency education" model: How normal could the projected new normal be? E3S Web of Conferences - in the current issue (2021)

10. L.A. Dikaya, G.A. Avanesyan, I.S. Dikiy, V.A. Kirik, V.A. Egorova, How Personality Traits are Related to the Attitudes Toward Forced Remote Learning During COVID19: Predictive Analysis Using Generalized Additive Modelling. Frontiers in Education (2021) doi: 10.3389/feduc.2021.629213

11. A.V. Grigoryev, The risks of digitalization of school education (based on an Astrakhan teachers survey). Society: sociology, psychology, pedagogy (2020) https://doi.org/10.24158/spp.2020.6.4

12. M. Henderson, N. Selwyn, R. Aston, What works and why? Student perceptions of 'useful' digital technology in university teaching and learning. Studies in Higher Education, 8(42), 1567-1579 (2017) https://doi.org/10.1080/03075079.2015.1007946

13. C. Hodges, S. Moore, B. Lockee, T. Trust, A. Bond, The difference between emergency remote teaching and online learning. Educause review, 27, 1-15 (2020)

14. I.S. Kochetkova, L.A. Terskaia, Experience in using the e-learning system (Moodle) in general scientific and special disciplines. Azimuth of Scientific Research: Pedagogy and Psychology, 4(21), 93-97 (2017)

15. N.A. Mullagaliev, N.V. Urazlina, On the attitude of students to the introduction of distance learning e lements in a university. Innovative science, 1(1), 188-191 (2017)

16. M.G. Sorokova, The digital educational environment of the university: Who is more comfortable studying in it?. Psychological Science and Education, 2(25), 44-58 (2020) https://doi.org/10.17759/pse.2020250204

17. E.A. Bryzgalin, A.E. Vojskunskij, S.A. Kozlovskij, Psychological analysis of practical experience in developing the online encyclopedia "Wikipedia". Siberian psychological journal, 73, 17-39 (2019). DOI: 10.17223/17267080/73/2. 
18. A.E Vojskunskij, Cyberpsychologist perspectives for the study of group forms of creative activity. Creativity in the modern world: human, society, technology, 22-23. Institute of psychology of RAS, Moscow (2020)

19. A.E. Vojskunskij, T.D. Yermolova, S.R. Yagolkovskij, V.M. Khromova, Creativity in online gaming: individual and dyadic performance in Minecraft. Psychology in Russia: State of the Art, 4(10), 144-161 (2017)

20. F. Biwer, W. Wiradhany, M.G.A. oude Egbrink, H. Hospers, S. Wasenitz, W. Jansen, A.B.H. De Bruin, Changes and Adaptations: How University Students Self-Regulate Their Online Learning during the COVID-19 Pandemic. Frontiers in Psychology (2021) doi: 10.3389/fpsyg.2021.642593

21. Z. Ismail, N. Halias, R. Md Saad, M.F. Mohamed, Motivation as the Mediator in Relationship between Non-verbal Communication of Arabic Language Teachers and Student Learning Outcomes. Universal Journal of Educational Research, 2(8), 700-708 (2020)

22. I.A. Poluekhtova, O. Yu. Vikhrova, E. L. Vartanova, Effectiveness of Online Education for the Professional Training of Journalists: Students' Distance Learning During the COVID-19 Pandemic. Psychology in Russia: State of the Art, 4(13), 26-37 (2020) DOI: 10.11621/pir.2020.0402

23. S. Rashid, S. S. Yadav, Impact of Covid-19 pandemic on higher education and research. Indian Journal of Human Development, 2(14), 340-343 (2020) DOI: 10.1177/0973703020946700

24. R.M. Bernard, P.C. Abrami, E. Borokhovski, R. Tamim A. Wade, M. Surkes, E. Bethel, A meta-analysis of three types of interaction treatments in distance education. Review of Educational Research, 3(79), 1243-1289 (2009) http://dx.doi.org/10.3102/0034654309333844

25. E. Borokhovski, R. M. Bernard, R. M. Tamim, R. F. Schmid, A. Sokolovskaya, Technology-supported student interaction in post-secondary education: A metaanalysis of designed versus contextual treatments. Computers \& Education, 96, 15-28 (2015) http://dx.doi.org/10.1016/j.compedu.2015.11.004

26. V. P. Zinchenko, B. G. Meshcheryakov, Psychological dictionary (Astrel, AST, Transitkniga, Moscow, 2006)

27. V. V. Zhovtonozhko, A historical analysis of the term of socio-psychological climate in Russian science. Vlast' 3, 163-167 (2016)

28. S. V. Alexandrova, The analysis of the psychological microclimate of the student group. Science and education: experience, problems, development prospects, 170-173 (Krasnoyarsk State agricultural university, Krasnoyarsk 2019).

29. T. Konold, D. Cornell, K. Shukla, F. Huang, Racial/ethnic differences in perceptions of school climate and its association with student engagement and peer aggression. Journal of youth and adolescence, 6(46), 1289-1303 (2017). DOI: 10.1007/s10964016-0576-1

30. G. G. Bear, C. Yang, D. Chen, X. He, J. S. Xie, X. Huang, Differences in school climate and student engagement in China and the United States. School Psychology Quarterly 2(33), 323-335 (2018). https://doi.org/10.1037/spq0000247

31. A. I. Dontsov, D. A. Dontsov, Methodological and diagnostic foundations of practical research of children, adolescents and youth groups and teams. Bulletin of Practical Psychology of Education, 1, 77-88 (2017)

32. A. O. Prokhorov, Methods for diagnosing and measuring mental states of the individual. (PER SE, Moscow, 2004). 
33. V.M. Zavyalova, Assessment of the microclimate of a student group. Sociopsychological diagnostics of the development of personality and small groups, 141-142 (Publishing house of the Institute of Psychotherapy, Moscow, 2002)

34. L. N. Sobchik, Methods of psychological diagnostics. Issue 3. Diagnostics of interpersonal relations. Modified version of T. Leary's interpersonal diagnostics. (Method Guide. Moscow, 1990).

35. A. V. Batarshev, I. Yu.,Alekseeva, E. V. Mayorova, Diagnostics of professionally important qualities. (Peter, Moscow, 2006).

36. E. V. Ermolaeva, L. A. Pavlova, Favorable social and psychological climate in the team as a condition for effective work. New science: theoretical and practical view, $\mathbf{3}$, 50-52 (2015)

37. A. V. Sidorenkov, N. Yu. Ulyanova, O. Yu. Shipitko, Modern foreign researches in psychology of conflicts in small groups. Psychological Journal, 6(38), 30-41 (2017) 